\title{
Pros

\section{REAPROPIACIÓN, DESCOLONIZACIÓN Y RESISTENCIA EN LA AUTOTRADUCCIÓN MAPUCHE: ADRIANA PAREDES PINDA, LILIANA ANCALAO, MARÍA TERESA PANCHILLO Y ELICURA CHIHUAILAF}

\author{
MeLISA Stocco \\ CONICET/ UNCuyo/ Freie Universität Berlin \\ meli.stocco@gmail.com
}

\begin{abstract}
RESUMEN: En nuestro análisis del carácter político de la autotraducción en la poesía mapuche contemporánea surgen dos aspectos: la singularidad de sus raíces sociohistóricas y sus alcances ético-políticos. Respecto de lo primero, consideraremos el concepto de "arreo" (Mellado 2014) para pensar las motivaciones sociohistóricas no atendidas por la traductología. En segundo lugar, y partiendo de la noción de "literatura menor" (Deleuze y Guattari 1978) analizaremos la autotraducción mapuche como contradispositivo de enunciación que se reapropia del castellano y busca poner al mapudungun en el mismo grado de legibilidad. Estas cuestiones serán interpeladas por textos de cuatro autores: Adriana Paredes Pinda, Liliana Ancalao, María Teresa Panchillo y Elicura Chihuailaf, en los cuales piensan su propia práctica escritural en dos lenguas.
\end{abstract}

PALABRAS CLAVE: autotraducción; poesía mapuche; literatura menor; arreo; resistencia

ABSTRACT: In our analysis of the political character of self-translation in contemporary Mapuche poetry, two aspects arise: the singularity of its socio-historical roots and its ethical-political scope. With respect to the first issue, we will consider the concept of "arreo" (Mellado 2014) to think the motivations of these forms of self-translation not sufficiently regarded by Translation Studies. Secondly, and bearing in mind the notion of "minor literature" (Deleuze y Guattari 1978), we will analyze Mapuche self-translation as a counterdispositive of enunciation to reappropriate the Spanish language and strive to put Mapuzungun at the same level of readability. These issues will be permanently confronted with texts of four authors: Adriana Paredes Pinda, Liliana Ancalao, María Teresa Panchillo and Elicura Chihuailaf, in which they reflect on their own bilingual writing.

KeY WORDS: Self-Translation; Mapuche Poetry; Minor Literature; Arreo; Resistance

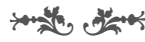




\section{INTRODUCCIÓN}

La poesía escrita por autores que se inscriben como miembros o descendientes de pueblos originarios de Latinoamérica puede ser considerada hoy como un territorio de agenciamiento indígena en plena apertura y despliegue, cuyo "resurgimiento y visibilización [...] representa[n] hoy día uno de los fenómenos culturales más novedosos en la región" (Del Valle Escalante 2013: 1). El caso puntual de la poesía mapuche contemporánea constituye un fenómeno atravesado por una gran amplitud de variables lingüísticas de acuerdo con los recorridos y devenires de los diferentes autores que componen una constelación dispersa por los territorios de Argentina (Puel Mapu) y Chile (Gulu Mapu). Tal variedad incluye tanto a quienes escriben solo en castellano como a los que también lo hacen en mapudungun. Asimismo, quienes trabajan en un doble registro puede que incorporen palabras de la lengua vernácula a sus textos ${ }^{1}$ o que escriban dobles versiones en sendas lenguas. De quienes elaboran su producción literaria en esta modalidad, encontramos tanto a hablantes del mapudungun como lengua materna aprendida de sus familias y comunidades en la infancia cuanto a aquellos que la han aprendido a posteriori, en un movimiento consciente de descolonización y (re)configuración de su identidad indígena.

Estas caracterizaciones son sin duda una simplificación de la realidad puesto que, además de tener en cuenta el grado de dominio de las lenguas en cuestión, la singularidad de las propuestas estéticas, conceptuales, ideológicas y estilísticas de cada poeta se refleja de diversas formas en sus textos. Sin restar importancia a esta evidente diversidad, me interesa aquí centrar el análisis en el procedimiento de autotraducción utilizado por muchos de estos autores.

En su fusión de las competencias del autor y del traductor, la autotraducción ha generado interesantes debates dentro del ámbito de la traductología. En ellos se la ha definido como una simple traducción, como una recreación (entendido su producto como un segundo original) o bien -y esta es la definición que escojo- como una creación que escapa a la secuencialidad temporal de original y versión, por tratarse de la escritura de un mismo autor que interpela dos espacios culturales en simultaneidad (Hokenson y Munson 2007: 207).

Consideramos que la situación actual de la literatura originaria en Latinoamérica es la manifestación cultural de un proyecto de agenciamiento indígena no solo de carácter lingüístico, sino también epistémico, político y estético (Arias et al 2012: 7) y en el despliegue de ese agenciamiento, la autotraducción castellano-lengua vernácula es una práctica central, pues pone de manifiesto una serie de contradispositivos de enunciación que se reapropian de la lengua colonizadora, buscan poner a la lengua indígena en el mismo grado de legibilidad y admisibilidad literaria que el castellano, a la vez que desnaturalizan y de-

\footnotetext{
1 Estas poéticas pueden asociarse a lo que Rodrigo Rojas denomina como "lengua escorada": "Una escritura en una lengua inclinada hacia otra. Esa otra no está presente en la página, no es una lengua ágrafa, sino un idioma olvidado a la fuerza. Mediante palabras incrustadas, sintaxis forzadas o elementos del texto orientados a la representación oral, se está dando peso y forma a un cuerpo ausente, a esa lengua otra" (2009: 143).
} 
safían miradas esencialistas ${ }^{2}$ sobre cuestiones tales como identidad, literaturas nacionales y lengua materna.

A continuación intentaremos analizar dos aspectos centrales de la práctica autotraductora indígena latinoamericana. Por un lado, nos proponemos pensar -en términos sociohistóricos situados- las posibles motivaciones de una escritura diglósica en el ámbito de la literatura indígena latinoamericana, en particular, en la poesía mapuche. Aquí problematizaremos cuestiones ligadas a los movimientos migratorios y consecuente adopción de una lengua y pérdida o borradura de otra.

Por otra parte, indagaremos en las características de la autotraducción en tanto contradispositivo de enunciación de una "literatura menor" (Deleuze y Guattari 1978). En este punto reflexionaremos sobre los alcances no solo literarios sino también éticos y políticos de la autotraducción.

En ambos casos no buscaremos establecer generalizaciones sino leer a los propios autores $y$, desde la cercanía de esas voces diversas, plantear nuestras reflexiones. Los autores seleccionados para este trabajo son: Adriana Paredes Pinda (Osorno, 1970), Liliana Ancalao (Comodoro Rivadavia, 1961), María Teresa Panchillo (Cholchol, Lof Kuyvmko, 1958) y Elicura Chihuailaf (Quechurewe, 1952). En este sentido, creemos importante tener en cuenta el planteo de Renate Eigenbrod acerca de una "ética de la posicionalidad" del lector de literaturas indígenas en tanto outsider. La estudiosa especialista en literaturas nativas del Canadá subraya como tarea del crítico la búsqueda de lo singular y el aprecio por la precisión más que los propósitos de generalización de conclusiones que pueden suponer una esencialización y homogeneización de la diversidad de voces:

Over the years, and responding to an increasing number of Aboriginal students in my classes, I learned better not to essentialize but to value their personal perspectives. Instead of looking for a representative voice, I started to appreciate "the accuracy" Basil Johnston explains as a cultural value. In fact, my own research and scholarship that evolved in parallel with my teaching became increasingly attuned to discerning differentiation and complexities within Native cultures and their literatures, eschewing colonial discourses of homogenization and reification. (Eigenbrod 2005: 9)

\footnotetext{
2 El tema del esencialismo sigue siendo uno de los más espinosos en este campo de estudios. Como resalta Juan Guillermo Sánchez recuperando las reflexiones desde una "ética de la posicionalidad" de la estudiosa germano-canadiense de literaturas indígenas Renate Eigenbrod: "Si el esencialismo en los discursos indígenas, entendido con Smith como una estrategia para exigir una posicionalidad auto-definida (incluyendo conceptos de la espiritualidad), es un empoderamiento de los pueblos indígenas, las definiciones esencialistas producidas por personas exógenas a la comunidad tienen el efecto opuesto": así, esencializar o ser ambiguo y contradictorio no son solo privilegios 'occidentales', sino parte de la agenda de los nativos-migrantes de hoy" (2014: 42). Por otra parte, ante la posible postura paternalista derivada de lo expuesto por Sánchez, creemos importante interponer en este debate la alternativa de "etnicidad táctica" desarrollada por Silvia Rivera Cusicanqui, como una categoría dinámica en oposición al concepto de "etnicidad" o "esencialismo estratégico": "La etnicidad estratégica, capturada por el estado y colocada como camisa de fuerza en el cuerpo de los pueblos indígenas amazónicos, resulta insuficiente y tramposa, anclada como está en la esfera discursiva y en un pensamiento dualista que postula esencias antes que procesos o prácticas colectivas. Por ello acudimos a una noción dinámica, la de etnicidad táctica, que alude al día a día del trabajo y de la lucha, en procura de visibilizar un potencial civilizatorio alternativo" (2014: 9).
} 
2. RAZONES SOCIOHISTORICAS DE LA AUTOTRADUCCIÓN EN LAS LITERATURAS INDÍGENAS: ¿EXILIO O "ARREO"?

Consideramos que las razones sociohistóricas de las que deriva la autotraducción en el caso de los autores indígenas no han sido suficientemente contempladas por los estudios de traducción que suelen referirse a esta práctica como motivada por el exilio o la inmigración y la adopción más o menos voluntaria de una nueva lengua para situar el propio trabajo en relación con figuras canónicas, convenciones y géneros en ambas tradiciones, la propia y la extranjera. Si bien existen movimientos migratorios en el caso de los pueblos originarios, ¿es válido hablar de situación de exilio? Creemos necesario considerar -por lo menos en el caso de los pueblos mapuche-tehuelche del área cultural sur a los que pertenecen los autores aquí estudiados-que la situación sociolingüística de los escritores y escritoras indígenas deriva de las políticas de despojo material y estigmatización sociocultural llevadas a cabo primeramente en épocas coloniales y luego por los estados nacionales latinoamericanos desde sus períodos de conformación territorial y de alineación de sus economías al modelo agroexportador capitalista hasta nuestros días.

En su ensayo "El idioma silenciado", la autora mapuche Liliana Ancalao reflexiona de la siguiente manera sobre el proceso de despojo y estigmatización al que referimos:

Fue el idioma del extenso camino del exilio, la distancia del destierro. La larga marcha de nuestros bisabuelos hacia las reservas. Ka mapu. A nuestros abuelos, les tocó ir a la escuela rural y hacerse bilingües a la fuerza. Aunque fue el proscripto de la escuela y los maestros enseñaron a los niños a avergonzarse del idioma que hablaban en su hogar, el mapuzungun siguió vigente. La lengua de la tierra estaba en el aire de la oralidad y "la castilla", en la escritura borroneada de los cuadernos. (Ancalao 2010: 50)

Para hablar de esta situación sociolingüística marcada por la acción de marginación de los poderes estatales y la educación occidentalizadora preferimos optar por el concepto de "arreo" elaborado por Silvia Mellado. Este término supone hablar, ya no en términos de exilio o éxodo sino en los de "ocupación y transacciones de tierras y cuerpos" (2014a: 85), es decir, hablar de los efectos producidos por el desplazamiento violento de las comunidades indígenas a los márgenes, empujadas por la acción militar de los estados nacionales a fin de apropiarse de territorios para incorporar a sus nacientes economías. Es muy ilustrativo en este caso volver a citar a Liliana Ancalao, cuando en su ensayo "Eso es lo que é", estudiado por Mellado en su trabajo La morada incómoda, se plantea la siguiente pregunta: "El nutram ${ }^{3}$ del exilio? El nutram del peregrinaje? Cómo llamarlo? [...]. Ni éxodo ni exilio. El nutram del arreo. De cuando el ejército argentino nos arreó como a animales" (2014a: 168-169).

${ }^{3}$ Nvtram: narración, relato, conversación, discurso, palabra, historia (Augusta 1991: 1: 152). 
En este "arreo" fuera de la zona productiva, el cuerpo y por ende la identidad de los pueblos originarios, con su lengua y su cultura, pasan al grado de marginación y estigmatización que supone en muchos casos la pérdida de la lengua al interior de las comunidades, cuya recuperación se da gradualmente de la manera como mencionáramos en la introducción o que aparece paradójicamente desde la ausencia en una palabra "escorada" en castellano (Rojas 2009).

Este concepto de "arreo" no puede, como plantea Edouard Glissant al hablar de las permutaciones del contacto cultural, ser generalizable (1989: 19). Tiene la especificidad de referir a la situación de desplazamiento en zonas de producción ganadera patagónica, en la que los cuerpos de los habitantes originarios de los territorios son vistos como mercancías de menos valor que el ganado, como cuerpos desechables destinados a ser reemplazados en la población de extensas porciones de territorio patagónico por vacas y ovejas. Así y todo, la reflexión situada que permite la noción de "arreo" puede asociarse a la que habilitan conceptos que refieren a la especificidad de otros movimientos materiales y procesos culturales de Latinoamérica y el Caribe como el de "pueblo trasplantado" del propio Glissant. No es lo mismo un pueblo exiliado que uno trasplantado, remarca Glissant, pues mientras ambos atraviesan la nostalgia de un origen unitario y una completitud originaria, en el caso de los descendientes de los pueblos trasplantados, el trabajo es aún más arduo por la borradura sistemática de la memoria colectiva (1989: 6-17).

Esta borradura contiene una carga trágica pero también una responsabilidad ético-política de reconfiguración de la identidad indígena contemporánea para autores como Adriana Paredes Pinda, quien en el prólogo a su poemario $\ddot{U i}(2005)$ sostiene:

Si la pérdida de la lengua es una tragedia [...] [l]a tragedia no sería un proceso de vida y muerte al mismo tiempo y en los tiempos y espacios diversos en los cuales se gesta nuestro vivir; nuestra tragedia entonces ha permitido la reconstrucción de un mundo no idéntico en sí [...] la reconstrucción de las matrices culturales, de unos pensares y sentires y habitares en y con la vida, no están agotados, se regeneran cotidianamente y no significa esto que de un día para otro todo se le ocurrió renacer, no se trata de eso; desde el instante previo a la muerte, ya comenzamos a renacer, comenzamos a desordenarnos y su vez, nos reordenamos tal cual pasa en la ñuke mapu, la madre. (Paredes Pinda 2005: 10)

Algo similar expresa Liliana Ancalao en su ensayo "Oralitura: una opción por la memoria":

La conciencia de ser parte de un pueblo nos hace ser responsables del resguardo de una cultura, porque la pérdida de la memoria, el olvido, que es una de las modalidades de la muerte, acecha a los pueblos originarios hoy. Memoria y conocimiento son sinónimos. Y esa es la otra herencia que nos corresponde: el conocimiento. Conocimiento al que hay que acceder primero, para luego hacerlo circular dentro de nuestro pueblo. (Ancalao 2005: 32) 
Ambas autoras pertenecen a aquel grupo de escritores que mencionamos más arriba como adquirente de la lengua ancestral en la adultez, paradójicamente como una segunda lengua. Esta contradicción abre una escisión al interior de la subjetividad. En términos de Paredes Pinda, se vive con "dos corazones":

Por qué escribo, se me ha preguntado [...], escribo porque tal vez es cierto que tengo dos corazones [...] si cantara sólo tendría un piuke, me habitaría uno, un aliento, una sangre, entonces no me atormentaría la semántica, ni la cognición ni los enfoques interpretativos [...] no he logrado zafarme del hechizo de esta escritura huinca porque me arranca y me arranca el aliento, estoy enferma posesa por el wekvfe de la escritura, condenada a la metáfora grecolatina [...] esta la lengua castellana ha matado mi alma, mi espíritu una y otra vez. [...] Escribo por puro anhelo de poder seguro. (Paredes Pinda 2005: 7)

Dos corazones, dos ámbitos de expresión, el canto mapuche y la escritura winka y el tormento de la influencia del castellano como lengua ligada al opresor y al poder: "la cultura escritural nos convierte en desolados y desoladas, nos hace herederos de su imperialismo discursivo, de su poder simbólico" (2005: 10-11).

En términos similares, aunque con una trayectoria sociolingüística distinta, la poeta María Teresa Panchillo destaca la contradicción de la escritura en la lengua del conquistador. Panchillo es una hablante nativa de la lengua mapudungun con plena competencia en la misma. En los siguientes versos la autora habla también de escisión, heridas antiguas marcadas a fuego en la memoria:

Escribo en las palabras de las mentiras

que degüellan el silencio de lo que está por destruirse.

Escribo en las palabras

de las culpas de tus versiones y las mías...

$Y$ no logro suturar las heridas sangrando en la memoria. (Panchillo en Falabella et al. 2009: 221-222)

En otro plano, Elicura Chihuailaf, también vernáculo-hablante de la lengua mapudungun desde su infancia, plantea la responsabilidad ética de la escritura en la lengua de su comunidad como figura mediadora entre culturas. Como sostiene Mellado en su estudio sobre la poesía de Chihuailaf: "El poeta es convocado para que lleve el recado y parlamente"4 (2014b) y, en ese rol, figura

\footnotetext{
${ }^{4}$ Aquí Mellado analiza el siguiente poema liminar de Sueños Azules y Contrasueños (1995):

Qué estás haciendo, sentado en la tierra

entristecido, sin parlamentar

Conversa pues, parlamenta

Qué tristeza verte así

Estás sentado en la pampa solamente

donde parlamentaban tus mayores

Sin movimiento yace tu tierra

Nada dices

Ponte de pie, parlamenta en tu tierra
} 
una función de diálogo intercultural de werken, weupüfe o lenguaraz (Rodríguez Monarca 2005).

Asimismo, el poeta plantea su escritura en mapudungun como parte de una acción esperanzada con vistas al futuro, en que sus descendientes no atraviesen la situación de pérdida de la lengua que se está dando de manera generalizada entre la población mapuche a ambos lados de la cordillera, sino que puedan leer sus textos bilingües con igual competencia en ambas lenguas. Como declara en el "Inicio" de su poemario El invierno, su imagen y otros poemas azules: "Escribo para las hijas y los hijos de mis hijas que -en el campo y la ciudad- leerán quizás mis poemas en mapudungun y en castellano, y reconocerán el lenguaje, el gesto que media entre ambas versiones" (1991: 7).

\section{LA AUTOTRADUCCIÓN COMO CONTRADISPOSITIVO DE ENUNCIACIÓN}

Creemos relevante pensar en la poesía mapuche contemporánea desde la categoría de "literatura menor" entendida como la plantean Deleuze y Guattari en tanto literatura de una minoría que desterritorializa una lengua mayor (1978: 28). Una de las características fundamentales de la literatura menor es la de constituirse en una máquina literaria con la que la enunciación individual del sujeto autor se vuelve colectiva, múltiple y por lo tanto revolucionaria. Dentro de los dispositivos de enunciación con los que contaría una literatura menor, proponemos poner a consideración el procedimiento de la autotraducción y acentuar su centralidad en la producción literaria de los pueblos originarios latinoamericanos.

¿Por qué centrar el análisis en la autotraducción? Entendemos que la siguiente idea de Deleuze y Guattari da una clave a esta pregunta:

Quizás el estudio comparado de las lenguas es menos interesante que el de las funciones del lenguaje que pueden ser ejercidas por un mismo grupo en lenguas diferentes: bilingüismo e incluso multilingüismo. Porque este estudio [...] escapa al mito "informativo" para evaluar el sistema jerárquico e imperativo del lenguaje como transmisión de órdenes, ejercicio del poder o resistencia a este ejercicio. (Deleuze y Guattari 1978: 39)

Consideramos la autotraducción como el procedimiento por excelencia detrás del uso de las funciones del lenguaje ejercidas por un mismo grupo en lenguas diferentes. Es posible hallar en los textos bilingües o multilingües producidos por grupos o sujetos pertenecientes a minorías la expresión de formas de resistencia, desdoblamiento, conflicto y construcción de subjetividad que hacen a la situación cultural del subalterno. A partir de esta reflexión y de otra afirmación de los filósofos franceses, a saber: "solo la expresión nos da el

aunque sientas tristeza, parlamenta

como lo hacían tus antepasados

como hablaban ellos

(me está diciendo el anciano Julián Weitra) 
procedimiento" (1978: 29), creemos vislumbrar en la autotraducción una clave para estudiar y pensar esta y otras literaturas menores, subalternas, descolonizadoras. Hay en el uso intensivo de las lenguas (expresión) que hace el autor/ autotraductor mapuche una desterritorialización que deconstruye y se reapropia de las lenguas: "Una literatura menor o revolucionaria comienza enunciando y solo después ve o concibe [...]. La expresión debe romper las formas, marcar las rupturas" (1978: 45).

A través de la autotraducción también se revela el gesto descolonizador de equiparar la lengua vernácula con la lengua adquirida del colonizador, lo cual configura una forma de resistencia al hacer fluir ambas lenguas por líneas de fuga, "hacia sus extremos o sus límites" encontrando con ello "las zonas de tercer mundo lingüísticas por donde una lengua se escapa" (1978: 44).

Para Deleuze y Guattari, la literatura menor expresa los dispositivos de enunciación "en las condiciones en que no existen en el exterior" (1978: 31). De hecho, el dispositivo de la autotraducción adquiere en este contexto un protagonismo particular, una centralidad que lo vuelve procedimiento de expresión privilegiado. Incluso es posible decir que, más allá del contenido de los textos bilingües, la fuerza de los mismos se encuentra ya en su materialidad, en tanto cuerpos dobles/desdoblados, metáforas o metonimias de la subjetividad del autor que vive en el "entremedio" de dos culturas, la hegemónica y la subalterna y que al analizar esta materialidad o expresión damos con el procedimiento de la autotraducción que la vuelve posible.

María Teresa Panchillo, en su poema bilingüe "Zukelewechi pu koyam/ Los hualles solitarios", transita las contradicciones de una escritura que busca reflejar la potencia de la naturaleza pero que sabe de sus limitaciones. Al mismo tiempo el poema expresa en ambas lenguas la pérdida del territorio y, en esa reapropiación del castellano y la puesta en pie de igualdad del mapudungun como lengua literaria, erige el texto desdoblado en testimonio y enunciado de resistencia colectiva:

\author{
Zukelewechi pu koyam \\ Zugukefule ga kisukelewechi pu koyam \\ lelfvn pvle \\ tefvafuy chi wiriwe tifa \\ wixuafuy kom pvle tapvh mew \\ chumgechi ga wixuy ñi mollfvñ, ñi kvlle \\ kakelu anvmka kom balewetulu \\ rupalu chi aukan \\ tvgvmgeam mapuche \\ wenteke wigkul tvfey \\ xayen mapa pvle.
}

Los hualles solitarios

Si hablaran los hualles solitarios 


\author{
En los campos \\ Se reventaría el lápiz escribiendo \\ La tinta correría por las hojas \\ Como corrió la sangre y lágrimas \\ De los otros árboles muertos \\ En la guerra que llamaron pacificación \\ Por estos cerros de XAYEN. (Panchillo en Falabella et al. 2009: 143)
}

El lápiz/árbol busca traducir el dolor de todos los caídos en la llamada "Pacificación de la Araucanía" (esos "otros árboles muertos") y en ese potencial intento se quebraría en su madera y manaría una tinta/sangre que trasciende el acto de la escritura y parece buscar una fusión con la memoria guardada en los bosques del sur.

Este trabajo con el potencial testimonial de la poesía, y su codificación en ambas lenguas, también se encuentra al final del poema "Ñi guyvgenoam". En este poema, en que la autora intercala una estrofa en mapudungun con su traducción al castellano, se hace una referencia directa a la lucha de las comunidades mapuche por la recuperación de las tierras ancestrales y el deseo de registrar en la palabra escrita la memoria de los movimientos populares. Ya el título es evidente en este sentido guyv deriva del verbo guyvn, "olvidar" (Augusta 1991: 1, 63), que, combinado con la preposición geno, "sin", está hablando del imperativo de no olvidar:

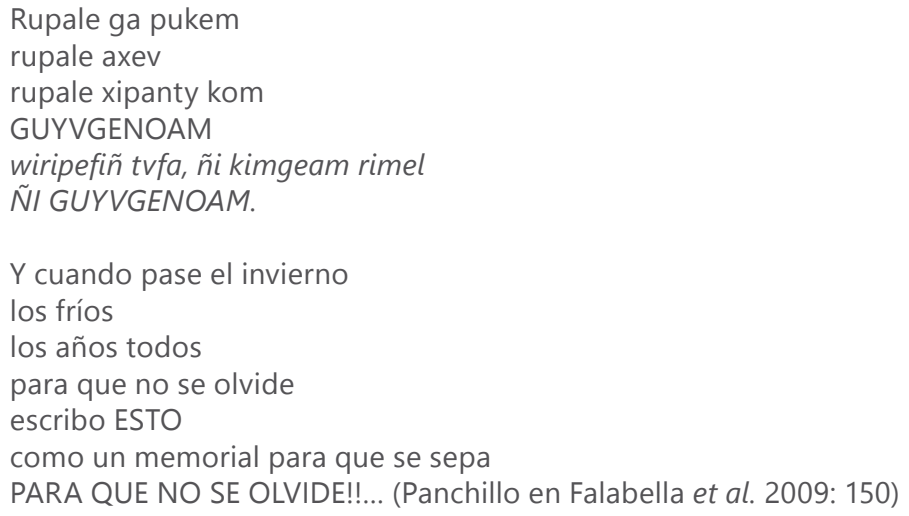

Esta misma inquietud por la recuperación de la memoria colectiva a través de la escritura autotraducida mapudungun/castellano la plantea Liliana Ancalao de la siguiente manera:

La tradición oral es el universo que se respira en el aire de nuestras reuniones, el universo incontenible dentro de nuestro cuerpo. La memoria. La memoria entre los antiguos había circulado solo en forma oral. Fue una decisión de nuestros pueblos usar los grafemas occidentales para escribir el idioma originario. Escribir la memoria en una pelea por defenderla del olvido. (Ancalao 2005: 33) 
Uso de los grafemas occidentales para poner en el centro al idioma silenciado junto con la memoria colectiva de su pueblo, pero también a la autotraducción:

¿Cómo se escribe esto que siempre anduvo en los árboles, tirado a la sombra de los helechos y los musgos, descolorido por el sol en las piedras de la estepa, salado en la transparencia de las orillas? [...] Se escribe en el idioma originario, en la lengua que sigue siendo materna, mapuzungun, aunque la aprendamos como segunda lengua, y también en el otro idioma: castellano, inglés, francés, portugués. (Ancalao 2005: 33)

En el vaivén entre lenguas es que la escritura florece, es que los significados se rebalsan y acometen como dos ríos en el punto de confluencia. De la misma manera, Elicura Chihuailaf habla del trabajo de la escritura interlingüística como una ida y vuelta, pero esta vez, entre el campo y la ciudad, entre la oralidad de la tradición ancestral situada en el tiempo de la infancia y en el territorio rural y la cultura de los textos y el ámbito citadino. Ese espacio sin nombre que habita es lo que Chihuailaf denomina "oralitura":

\begin{abstract}
Un espacio lleno de las susurrantes y potentes voces -cuentos / cantos / consejos / ruegos- de mis Mayores y Antepasados, mas también con las resonancias de las voces de las y los narradores y poetas universales. La tarea de la palabra poética, me dicen, es nombrar lo que aún no tiene nombre. Me di cuenta que no requería de un "lugar ni condición especial" para escribir [...]. En una difícil historia de exilios en las ciudades y regresos a mi comunidad, eran poemas pensados en castellano unos y en mapuzugun otros y que luego van desde el mapuzugun al castellano unos y desde el castellano al mapuzugun otros, más unos que se quedaron en castellano y algunos que se quedaron en mapuzugun. (Chihuailaf en Mellado 2014a: 160-161)
\end{abstract}

En Adriana Paredes Pinda la creación poética es vista con un sesgo de mayor pesimismo pero con un similar sentido del poder de resistencia de la escritura. Como plantea Gilda Luongo: "Pinda asienta el lugar ladrón de la lengua castellana, del español. Esta es la razón por la cual escribe: el robo legalizado de la lengua mapudungun por la lengua castellana. La escritura poética contiene la pérdida. Entonces la creación poética de esta autora no puede ser un don. Es un asalto" (2014: 90). Dice Pinda: "escribo bajo estado hipnótico y no logro zafarme; esta lengua meretriz me pesa, me quema, este weñefe, este pensar weñefe de mí, este espíritu weñefe de mí que vino de afuera y mató el dentro, y nos ha poseído a unos más que otros, pero posesos al fin hemos perdido nuestra razón" (2005: 9-10).

A pesar del lastre que supone la pérdida de la lengua ancestral, Pinda dice respecto del rol político de la(s) lengua(s) en el apartado "Foros Virtuales" de la antología Hilando en la memoria:

La palabra siempre ha sido herramienta de lucha, desde que se nace en ella, se pervive en ella, se transmuta en ella. Creo que la palabra es capaz de todo 
y nada, de repente puede ser tremendamente inocua y otras veces, puede ser letal [...] en todo caso siempre habrá guerreros de la palabra, impasibles al roce del tiempo, incrédulos a la desesperanza, resistentes a la derrota, guerreros del pensamiento, claro que los hay y por suerte, sino... qué sería de nosotros... (Paredes Pinda en Falabella et al. 2009: 222-223)

Y es ella misma una de esas guerreras, una poeta que sin miedos, como Ancalao, acomete la tarea de escribir también en mapudungun como forma de autorreconstrucción y empoderamiento:

... cuando yo escribo en mapudungun es algo instintivo, generalmente lo hago porque me sale, me nace, es como si pariera, a pesar de que podría estar mal escrito, como no soy hablante y como mapuche es un desafío. Es como un acto heroico, yo valoro eso, porque estoy honrando a mis abuelos. Yo no podría cantar solamente, yo soy una bestia escritural, yo nací en la escritura, en el castellano, pero estoy tratando de recuperar mi memoria oral, porque es una necesidad de vida, no por una "performance". (Ancalao en Falabella et al. 2006: 150)

\section{CONCLUSIONES}

En el presente trabajo hemos intentado analizar algunos aspectos del alcance que la práctica autotraductora tiene para los poetas mapuche contemporáneos desde una perspectiva ético-política e histórica. Para ello, hemos contado con nociones teóricas pero también con las propias reflexiones metaliterarias de los autores elegidos.

En primer lugar hemos propuesto contemplar las razones históricas que han motivado la situación sociolingüística de los autores mapuche que se autotraducen. En lugar de pensar la autotraducción como motivada por el exilio o la inmigración y la consecuente adopción de una lengua para ingresar a un determinado sistema literario, vemos en la autotraducción mapuche el resultado de los movimientos migratorios impuestos a las comunidades por políticas coloniales primero y nacionales después, con sus resultantes de despojo material y estigmatización cultural. Hemos elegido el concepto de "arreo" (Mellado 2014a) para entender este panorama desde un pensamiento situado en el área cultural sur mapuche-tehuelche a la que pertenecen dichos autores.

Estos factores supusieron en numerosas ocasiones la pérdida de la lengua vernácula, el mapudungun, al interior de las comunidades. Esta particular situación sociolingüística ha llevado a algunos autores (Paredes Pinda y Ancalao son ejemplos analizados en este trabajo) a aprender la lengua de sus ancestros en la adultez en un movimiento de recuperación identitaria. La borradura histórica de la lengua indígena se ve entonces desafiada por los autores y autoras que escriben sus textos de forma bilingüe e intentan poner al mapudungun en el mismo nivel de legibilidad y admisibilidad literarias que el castellano.

Esta práctica puede entenderse entonces como una puesta en acción de un dispositivo de enunciación propio de una literatura menor (Deleuze y 
Guattari 1978), que pone en evidencia un ejercicio de resistencia a las jerarquías y territorializaciones entre lenguas. Asimismo, los autores reflexionan desde sus metatextos sobre el carácter ético-político de su decisión de autotraducirse. Se manifiesta el deseo de trascender hacia un tiempo en que el mapudungun sea tan valorado como el castellano y de ejercer un rol mediador entre lenguas y culturas (Chihuailaf), de hablar de la memoria perdida y de los que resistieron y resisten (Ancalao, Panchillo) o de instaurar en la escritura una herramienta de lucha y autorreconfiguración (Paredes Pinda).

La palabra autotraducida produce textos bilingües que no solo rebalsan en sus significados literarios y estéticos (eso corresponde a otros trabajos en curso), sino en sus alcances políticos en tanto gesto descolonizador en el ámbito literario, de reconstitución de una identidad borrada con las particularidades de lo contemporáneo y de recuperación y puesta en pie de igualdad de una lengua perdida o invisibilizada frente al castellano. En definitiva, la práctica autotraductora permite devolver el nvtram, el relato, la conversación, el habla que recuerda en su discurrir lo perdido y lo silenciado. Como dice Liliana Ancalao:

Hablo de Puel Mapu y de la historia de mi familia que es la historia de muchas familias y que explica la pérdida de nuestro idioma como primera lengua, en la mayoría de mi generación. Hablo de una lengua milenaria y la ignorancia de los hombres que proyectaron un país sobre un territorio pleno de nombres, fuerzas y significados; silenciándolo. Hablo de lo que nos perdimos. Todos. (Ancalao 2010: 51)

\section{Obras Citadas}

Ancalao, Liliana (2005): "Oralitura: una opción por la memoria", El camarote, n. ${ }^{\circ}$ 5, pp. 32-33. — (2010): "El idioma silenciado", Boca de sapo, n. ${ }^{\circ}$ 6, pp. 49-51.

Arias, Arturo; Carcamo-Huechante, Luis; y Valle Escalante, Emilio del (2012): "Literaturas de Abya Yala", Lasaforum, vol, XLIII, n. ${ }^{\circ} 1$, pp. 7-10.

Augusta, Fray Félix José de (1991): Dicionario Araucano. Mapuche-Español. Español-Mapuche. Temuco, Kushe.

Chihuailaf, Elicura (1991): El invierno, su imagen y otros poemas azules. Santiago de Chile, Literatura Alternativa.

Deleuze, Gilles, y Guattari, Felix (1978): Kafka: por una literatura menor. Trad. Jorge Aguilar Mora. México, Era.

Del Valle Escalante, Emilio (2013): "Teorizando las literaturas indígenas contemporáneas: Introducción", A Contracorriente, vol. 10, n. ${ }^{0} 3$, pp. 1-20.

Eigenbrod, Renate (2005): Travelling Knowledges. Positioning the Im/Migrant Reader of Aboriginal Literatures in Canada. Winnipeg, University of Manitoba Press.

Fallabella, Soledad; Huinao, Graciela; y Rupailaf, Roxana (eds.) (2009): Hilando en la memoria. Epu rupa. Santiago de Chile, Cuarto Propio.

Fallabella, Soledad; Huinao, Graciela; y Ramay, Alison (eds.) (2006): Hilando en la memoria. 7 mujeres mapuche. Santiago de Chile, Cuarto Propio. 
Glissant, Edouard (1989): Caribbean Discourse. Trad: J. Michael Dash. Charlottesville, University Press of Virginia.

Hokenson, Jan Walsh, y Munson, Marcella (2007): The Bilingual Text: History and Theory of Literary Self-Translation, Manchester / Nueva York, St. Jerome Publishing.

Luongo, Gilda (2014): "Memoria y revuelta en poetas mujeres mapuche: intimidad/lazo social ॥", Aisthesis, n. ${ }^{\circ}$ 56, pp. 83-100.

Mellado, Silvia (2014a): La morada incómoda: Estudios sobre poesía mapuche. Elicura Chihuailaf y Liliana Ancalao. General Roca, PubliFadecs.

— (2014b): "Lenguas kuñifal: pasajes entre el mapuchezungun y el castellano en Elicura Chihuailaf, Liliana Ancalao y Adriana Paredes Pinda", Recial, n. ${ }^{\circ}$ 5-6. Disponible en<http://revistas.unc.edu.ar/index.php/recial/article/view/9586/10354> [última visita: 14.12.2015]

Paredes Pinda, Adriana (2005): Üi. Santiago de Chile, Lom.

Rivera Cusicanqui, Silvia (2014): Mito y desarrollo en Bolivia. El giro colonial del gobierno del MAS. La Paz, Piedra Rota / Plural.

Rodríguez Monarca, Claudia (2005): "Weupüfes y machis: canon, género y escritura en la poesía mapuche actual", Estudios Filológicos, n. ${ }^{\circ} 40$. Disponible en <http://dx.doi. org/10.4067/S0071-17132005000100011> [última visita: 14.12.2015].

Rojas, Rodrigo (2009): La lengua escorada. La traducción como estrategia de resistencia en cuatro poetas mapuche. Santiago de Chile, Pehuén.

Sánchez Martínez, Juan Guillermo (2014): Nativos migrantes: poesía en la encrucijada. Tesis doctoral inédita. University of Western Ontario. 